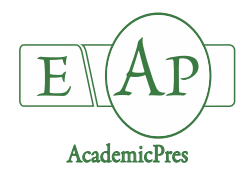

Zhang X et al. (2020)

Notulae Botanicae Horti Agrobotanici Cluj-Napoca 48(1):140-149

DOI: $10.15835 /$ nbha 48111840

Research Article

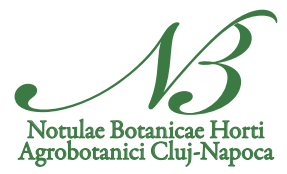

\title{
Effect of exogenous gibberellin on endogenous hormone and ginkgolide content in Ginkgo leaves
}

\section{Xian ZHANG ${ }^{1}$, Jun ZHU ${ }^{1}$, Shuiyuan $\mathrm{CHENG}^{2}$, Weiwei ZHANG ${ }^{1 *}$, Feng $\mathrm{XU}^{1 *}$, Yongling $\mathrm{LIAO}^{1}$}

${ }^{1}$ Yangtze University, College of Horticulture and Gardening, Jingzhou 434025, Hubei, China; zhang_xian722@163.com;

zhujun117@163.com;wwzhangchn@163.com (*correspondingauthor);xufeng@yangtzeu.edu.cn (*corresponding author);

liaoyongling@yeah.net

${ }^{2}$ Wuban Polytechnic University, School of Biology and Pharmaceutical Engineering, Wuban 430023, Hubei,

China;s_y_cheng@sina.com

\begin{abstract}
Ginkgolide is one of the important secondary metabolites of Ginkgo biloba. The synthesis of plant secondary metabolites is influenced by exogenous phytohormones. In this study, ten-year-old ginkgo grafted seedlings were used as the test material, and the effects of $0,2,4,6,8$, and $10 \mathrm{mmol} \mathrm{L}^{-1}$ gibberellin $\left(\mathrm{GA}_{3}\right)$ on endogenous indole acetic acid (IAA), abscisic acid (ABA), $\mathrm{GA}_{3}$, and ginkgolide contents in ginkgo leaves were investigated. Results showed that exogenous $\mathrm{GA}_{3}$ treatment inhibited endogenous $\mathrm{GA}_{3}$, changed the contents of endogenous IAA and ABA in ginkgo leaves, and affected the accumulation of secondary metabolite ginkgolides. Among the given concentrations, the $4 \mathrm{mmol} \mathrm{L}^{-1} \mathrm{GA}_{3}$ treatment could remarkably increase ginkgolide content. We found that the best harvesting period of ginkgo leaves were in late August and late September, in which the content of ginkgolides was the highest.
\end{abstract}

Keywords: abscisic acid; gibberellin; Ginkgo biloba; ginkgolide; indole acetic acid

\section{Introduction}

Ginkgo biloba (G. biloba), also known as Gongsun tree, is the only surviving species of Ginkgoaceae and the oldest relict plant of the gymnosperm left after the Quaternary glacier movement; hence, G. biloba is regarded as a "living fossil" and "panda of the plant kingdom" ( Tian et al., 2017; Ye et al., 2020). The active constituents of $G$. biloba leaves are mainly flavonoids and ginkgolides compounds (Ye et al., 2019). Ginkgolide have a variety of pharmacological activities, such as antiplatelet aggregation factor, central nervous system protection, antibacterial and anti-inflammatory effects, antiviral and anticancer effects, anti-allergic effects, anti-shock effects, protective effects on ischemic injury, and antirejection in organ transplantation (Liao et al., 2006; Tian et al., 2017). Ginkgolide has a role in regulating nerves, and pure ginkgolide B (GB code BN52021) is clinically used in treating stroke, organ transplant rejection, hemodialysis, and shock (Hu et al., 2017). Since the 1980s, the unique pharmacological value of ginkgolide has caused an international upsurge in the study of G. biloba. 
Gibberellin $\left(\mathrm{GA}_{3}\right)$ is a broad-spectrum plant growth regulator that promotes plant growth and development, early maturity, yield, and quality improvement. $\mathrm{GA}_{3}$ can quickly break the dormancy of organs, such as seeds, tubers, and bulbs; promote germination; reduce bud, flower, bell, and fruit shedding; increase fruit yield; or form seedless fruits (Niu et al., 2016; Vera-Sirera et al., 2016). In addition, Ülger et al. (2018) sprayed exogenous $\mathrm{GA}_{3}$ on 'Memecik' olive cultivar and found that its abscisic acid (ABA), $\mathrm{GA}_{3}$, indole acetic acid (IAA), and zeatin content increased considerably. Zhang et al. (2018) found that $\mathrm{GA}_{3}$ regulated the synthesis and decomposition of cytokinin, which upregulated the expression levels of $A$-IPTI and tRNADMATase genes but downregulated the expression levels of CYP735A, CKX1, and CKX2 genes. Guo et al. (2000) studied the effect of exogenous growth regulators on paclitaxel synthesis by applying exogenous $\mathrm{GA}_{3}$ and found that the application of exogenous $\mathrm{GA}_{3}$ could inhibit the synthesis of endogenous $\mathrm{GA}_{3}$ through feedback inhibition and results in the accumulation of intracellular geranylgeranyl pyrophosphate (GGPP), which increases paclitaxel content. Ginkgolide and $\mathrm{GA}_{3}$ are diterpenoids with the same precursor synthesis pathway (Ke et al., 2016). By applying exogenous $\mathrm{GA}_{3}$ to inhibit the synthesis of endogenous $\mathrm{GA}_{3}$, GGPP accumulation may be converted to the synthesis direction of ginkgolides to increase ginkgolide content.

Therefore, this paper studied the effects of different concentrations of exogenous $\mathrm{GA}_{3}$ on ginkgolides and endogenous hormones to provide technical support and theoretical guidance for the screening and improving the regulation measures of ginkgolide content in production.

\section{Materials and Methods}

\section{Plant materials and $G A_{3}$ treatments}

Ten-year-old grafted seedlings of G. biloba cv. 'Jiafoshou' were as experiment planted in Ginkgo Science and Technology Park of Yangtze University. The tree is moderate, and the growth is basically the same. All seedlings were treated by foliar sprayed with aqueous solutions of $\mathrm{GA}_{3}$ (containing $0.01 \%$ Tween 20 , $\mathrm{pH} 5.8$ ) at six concentrations of 0 (the control), 2, 4, 6, , and $10 \mathrm{mmol} \mathrm{L}^{-1}$ from June 25. The leaves were sampled from July 10 to October 25 by random stratification sampling method, and one hundred leaves with uniform size, uniform leaf colour, and no injury were randomly picked from similar branches with the same growth potential every fifteen days. Harvested ginkgo leaves were divided into two parts. One part was frozen in liquid nitrogen and stored in a refrigerator at $-80^{\circ} \mathrm{C}$ for the determination of endogenous hormone content in the leaves. The other part was washed and dried immediately, dried at $105^{\circ} \mathrm{C}$ for $20 \mathrm{~min}$ or $85^{\circ} \mathrm{C}$ for constant weight and grinding, and stored in the dryer for the measurement of ginkgolide content.

\section{Detection of endogenous hormones and ginkgolide content}

Endogenous hormone testing was performed following the method of Zhu et al. (2010). Endogenous hormones IAA, $\mathrm{ABA}$, and $\mathrm{GA}_{3}$ in $G$. biloba leaves were extracted with $80 \%$ precooled methanol aqueous solution. The target hormone was further purified by SEP-C18 small-column solid-phase extraction technique and detected by high-performance liquid chromatography with diode-array detection. A $10 \%$ methanol solution was finally selected as the washing solution by a preferred method, and $65 \%$ methanol solution was used as the elution solution. Column: Waters ODS-C18 column $(4.6 \mathrm{~mm} \times 250 \mathrm{~mm}, 5 \mu \mathrm{m})$; mobile phase: methanol-water-acetic acid (volume ratio $=54: 45.2: 0.8)$ mixture $(\mathrm{pH} 3.5)$, flow rate $1.0 \mathrm{~mL} \mathrm{~min}{ }^{-1}$; Column temperature: $40^{\circ} \mathrm{C}$; water 2,996 PDA detector; injection volume: $20 \mu \mathrm{L}$. Quantification was done through an external standard method. Hormone concentrations were expressed in microgram per gram of fresh sample (FW). Ginkgolide content was determined via large-caliber capillary gas chromatography separation and determination (Liao et al., 2008). Standard gingkolide A, ginkolide B, ginkolide C, and bilobalide were provided by the China National Institute for the Control of Pharmaceutical and Biological Products. Ginkgolide concentrations are expressed in microgram per gram of dry sample (DW). 


\section{Statistical analysis}

Design of the experiments was completely randomized with three replications. All data were processed using Excel, SPSS 22 and OriginPro 9.0 software. Duncan method $(\mathrm{P}<0.05)$ was used in comparing differences.

\section{Results}

\section{Effect of $\mathrm{HA}_{3}$ on endogenous $\mathrm{IAA}$ content in ginkgo leaves}

Seasonal variation in the content of endogenous hormone IAA in ginkgo leaves treated with different concentrations of $\mathrm{GA}_{3}$ was analysed. As shown in Figure 1, the IAA content of ginkgo leaves treated with different concentrations of $\mathrm{GA}_{3}$ showed a similar trend over time. In the annual harvest period, the IAA values detected in each treatment level were significantly higher than those in the control group, and the annual peak appeared on July 25, when all treatment levels were at their peak. The IAA content of the $8 \mathrm{mmol} \mathrm{L}^{-1}$ treatment group was $45.59 \mathrm{\mu g} \mathrm{g}^{-1} \mathrm{FW}$, which was the highest content during the peak period of July 25 . This hormone concentration was remarkably higher than the hormone concentrations in other treatment levels and then began to decrease. After IAA content dropped to the bottom of the valley on August 25, IAA began to rise again, rose to a secondary peak on September 10, and then gradually decreased until the end of sampling. IAA content in the $6 \mathrm{mmol} \mathrm{L}^{-1}$ treatment group showed no significant difference from that in the $8 \mathrm{mmol} \mathrm{L}^{-1}$ treatment group on July 25 and August 10 but was markedly lower than that in the $8 \mathrm{mmol} \mathrm{L}^{-1}$ treatment group in other sampling times. The longitudinal comparison of the whole harvest period showed that the annual average content of IAA at the $8 \mathrm{mmol} \mathrm{L}^{-1}$ treatment level was the highest, whereas IAA content in the $2 \mathrm{mmol} \mathrm{L}^{-1}$ treatment level was remarkably lower than the IAA contents in other treatment levels.

\section{Effect of $G A_{3}$ on endogenous $A B A$ content in ginkgo leaves}

Changes in endogenous hormone $\mathrm{ABA}$ in ginkgo leaves were detected by treating ginkgo leaves with different concentrations of $\mathrm{GA}_{3}$. It was shown in Figure 2 that after treatment with different concentrations of $\mathrm{GA}_{3}$, the change trend of $\mathrm{ABA}$ content in ginkgo leaves was similar in different periods, and the difference between groups was small. The ABA values of each treatment level were considerably higher than $A B A$ value in the control group during the annual harvest period. After a peak appeared on August 25, the ABA content in the later sampling period increased until the end of sampling. On August 25, September 10, and September 25 , the $\mathrm{ABA}$ content of the $2 \mathrm{mmol} \mathrm{L}^{-1}$ treatment group was substantially higher than that of the control group, whereas no significant difference was found between the rest of the samples and the control group. ABA content in the $8 \mathrm{mmol} \mathrm{L}^{-1}$ treatment group was high during the whole sampling period and was significantly different from the control group. The highest ABA content was $6.39 \mu \mathrm{g} \mathrm{g}^{-1} \mathrm{FW}$ in the $8 \mathrm{mmol} \mathrm{L}^{-1}$ treatment group during the peak period on August 25, when no significant difference was observed with other treatment groups. $\mathrm{ABA}$ content of the $4 \mathrm{mmol} \mathrm{L}^{-1}$ treatment group was five periods of that of the control group, whereas ABA contents of the 6 and $10 \mathrm{mmol} \mathrm{L}^{-1}$ treatment groups were six periods of that of the control group, and no significant difference was found between the remaining sampling tests and the control group. The differences between the 4, 6 and $10 \mathrm{mmol} \mathrm{L}^{-1}$ treatment groups were not significant, except that the ABA content in the $10 \mathrm{mmol} \mathrm{L}^{-1}$ treatment group was remarkably lower than that in the $6 \mathrm{mmol} \mathrm{L}^{-1}$ treatment group on July 25 and that in the $4 \mathrm{mmol} \mathrm{L}^{-1}$ on September 10; ABA content in the $4 \mathrm{mmol} \mathrm{L}^{-1}$ treatment group was significantly higher than that in the 6 and $10 \mathrm{mmol} \mathrm{L}^{-1}$ treatment groups on September 25; ABA content in the $10 \mathrm{mmol}$ $\mathrm{L}^{-1}$ treatment group was significantly higher than ABA contents in the 4 and $6 \mathrm{mmol} \mathrm{L}^{-1}$ treatment groups on October 10. Longitudinal comparison of the whole harvest period showed the annual ABA content of each treatment level had no significant difference with the control group. 
$\mathbf{A}$
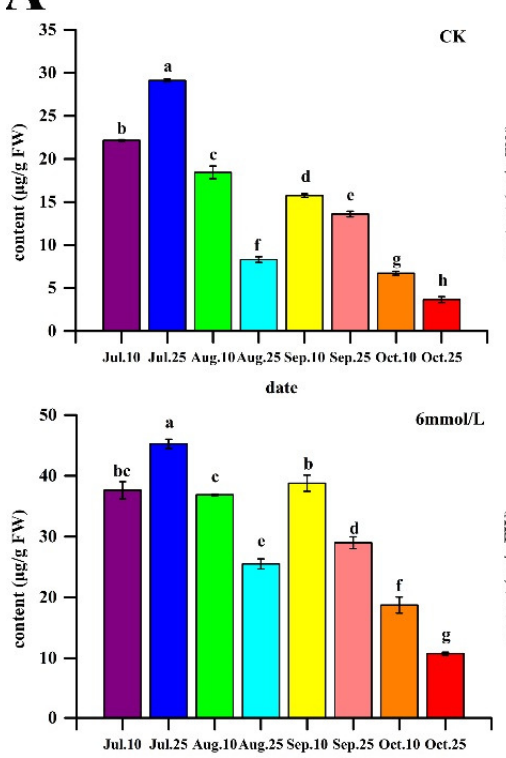

date

B

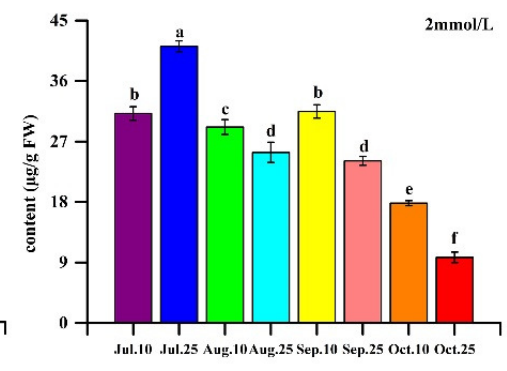

date

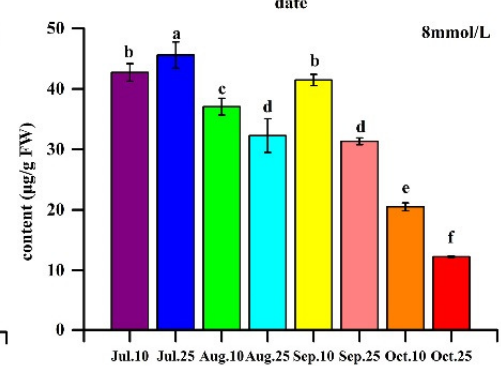

date
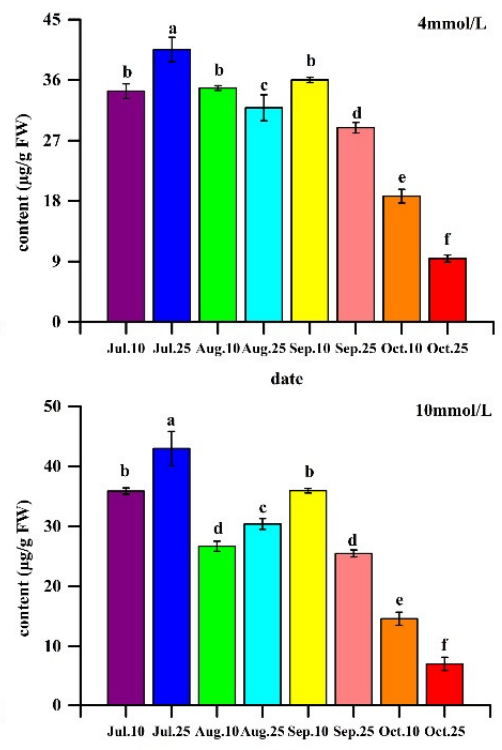

date
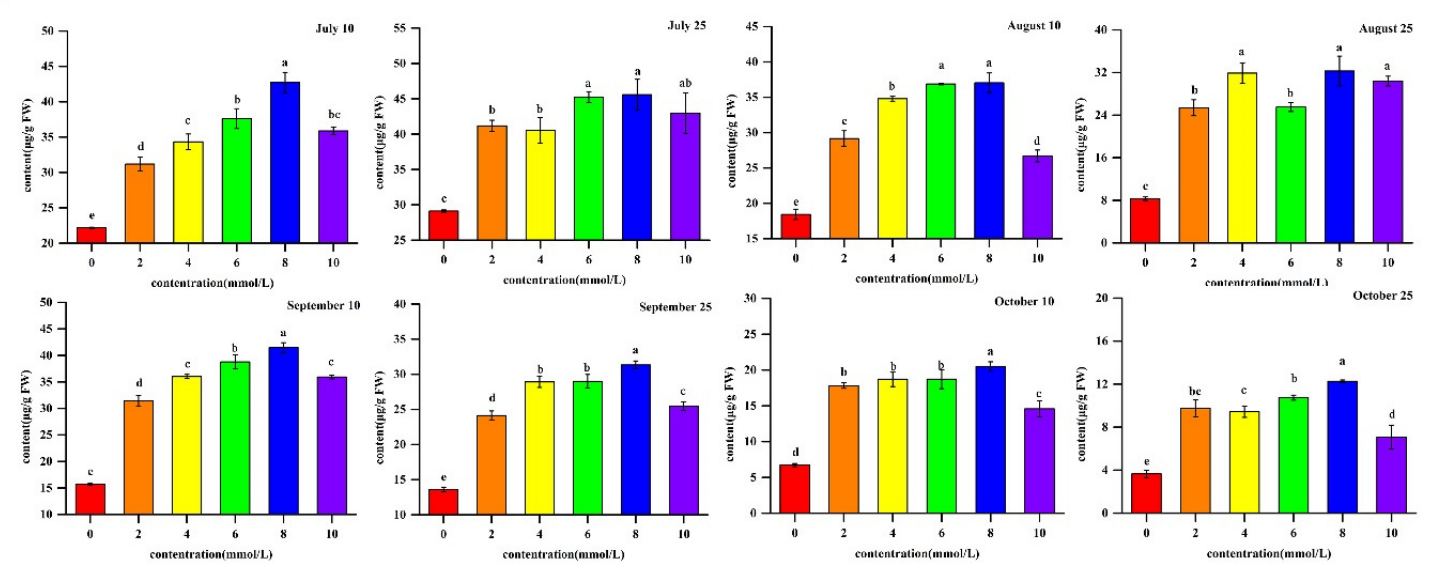

Figure 1. Effect of $\mathrm{GA}_{3}$ on the content of endogenous IAA in ginkgo leaves. Endogenous IAA content in ginkgo leaves at different peroids (A) and endogenous IAA content in ginkgo leaves treated with different concentrations of $\mathrm{GA}_{3}(\mathrm{~B})$ 
A

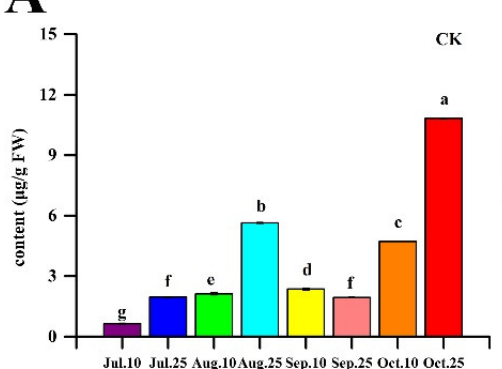

Jul.10 Jul.25 Aug.10Aug.25 Sep.10 Sep.25 Oct.10 Oct.25 date

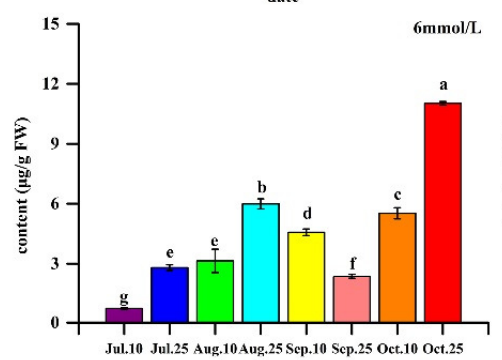

date

B
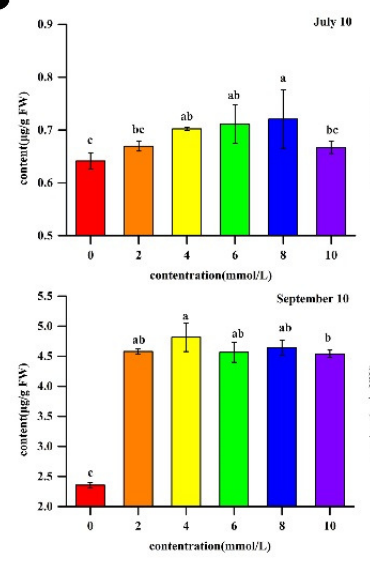

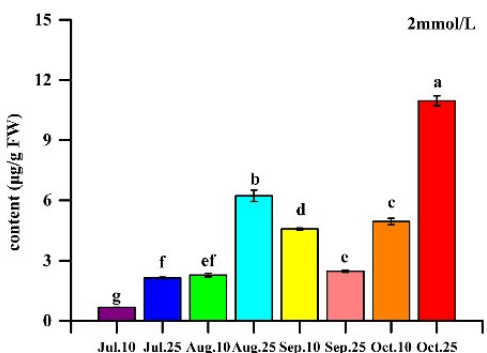

date

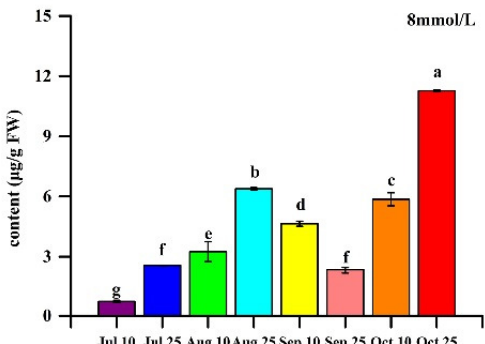

date

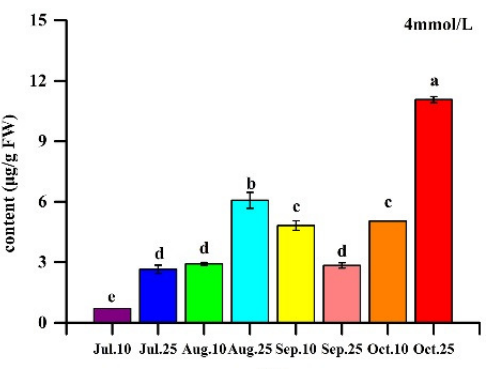

date

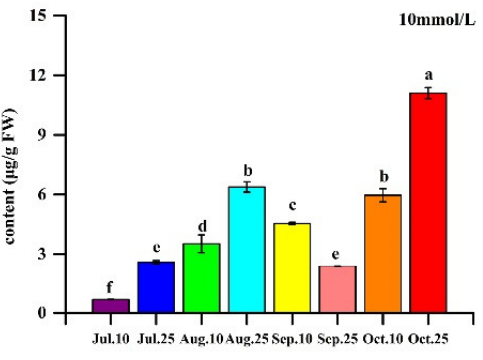

date

Figure 2. Effect of $\mathrm{GA}_{3}$ on the content of endogenous ABA in ginkgo leaves. Endogenous $\mathrm{ABA}$ content in ginkgo leaves at different peroids $(\mathrm{A})$ and endogenous $\mathrm{ABA}$ content in ginkgo leaves treated with different concentrations of $\mathrm{GA}_{3}(\mathrm{~B})$

\section{Effect of $G A_{3}$ on endogenous $G A_{3}$ content in ginkgo leaves}

We analysed the effect of exogenous $\mathrm{GA}_{3}$ on the content of endogenous hormone $\mathrm{GA}_{3}$ in ginkgo leaves. As shown in Figure 3, the general variation trend of endogenous $\mathrm{GA}_{3}$ content in ginkgo leaves treated with different concentrations of $\mathrm{GA}_{3}$ was similar, but the endogenous $\mathrm{GA}_{3}$ in the control group was significantly higher than that in the test treatment group. Results showed that the higher exogenous $\mathrm{GA}_{3}$ concentration, the lower endogenous $\mathrm{GA}_{3}$ detected in the treatment groups. Endogenous $\mathrm{GA}_{3}$ content in the experimental and control groups began to decrease starting from the initial sampling but began to rise at the end of July until a peak appeared on August 10. Then, the endogenous $\mathrm{GA}_{3}$ content of each treatment level began to decrease slowly until around September 10, when endogenous $\mathrm{GA}_{3}$ content was the lowest. Afterwards, endogenous $\mathrm{GA}_{3}$ rose again and reached a second peak on September 25. At the beginning of sampling (the whole month of July), the endogenous $\mathrm{GA}_{3}$ content of the control group was significantly higher than that of the treatment groups, and the endogenous $\mathrm{GA}_{3}$ content in the 2 and $4 \mathrm{mmol} \mathrm{L}^{-1}$ treatment groups was greatly higher than 
that in the 6,8 , and $10 \mathrm{mmol} \mathrm{L}^{-1}$ treatment groups. Subsequently, the endogenous $\mathrm{GA}_{3}$ content of each group began to rise; however, the content increase rate of the $8 \mathrm{mmol} \mathrm{L}^{-1}$ treatment group was higher than that of the 6 and $10 \mathrm{mmol} \mathrm{L}^{-1}$ treatment group. In August, the endogenous $\mathrm{GA}_{3}$ content of the $8 \mathrm{mmol} \mathrm{L}^{-1}$ treatment group was substantially higher than contents in the 6 and $10 \mathrm{mmol} \mathrm{L}^{-1}$ treatment group. On September 10, the endogenous $\mathrm{GA}_{3}$ content of the control group was lower than contents of the 2 and $4 \mathrm{mmol} \mathrm{L}^{-1}$ treatment group for the first time. Subsequently, the variation trend of $\mathrm{GA}_{3}$ content in each group was similar to that in the control group. Longitudinal comparison of the mean value of the whole harvest period showed that the annual average endogenous $\mathrm{GA}_{3}$ content was the lowest at the treatment level of $10 \mathrm{mmol} \mathrm{L}^{-1}$.

A

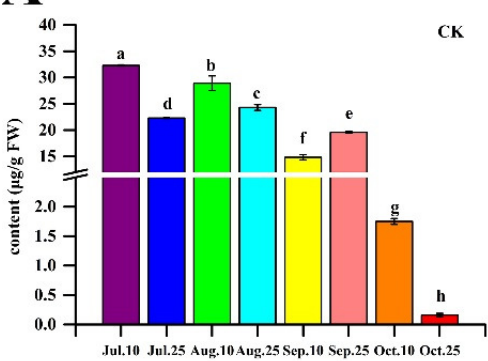

date

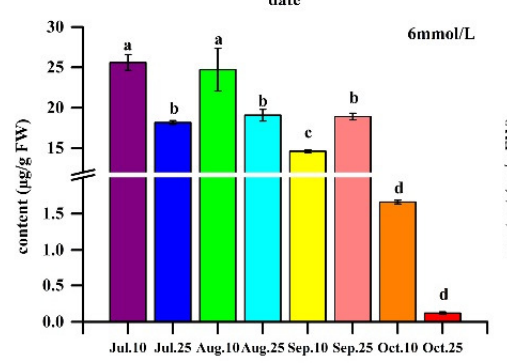

B
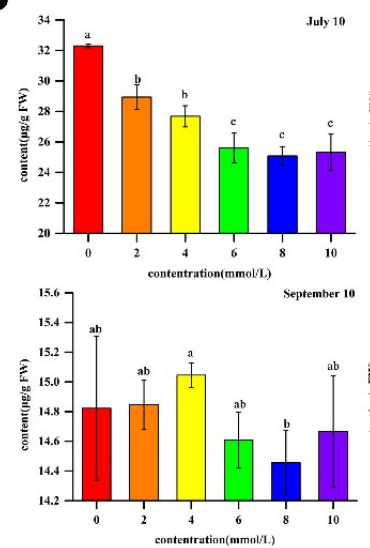

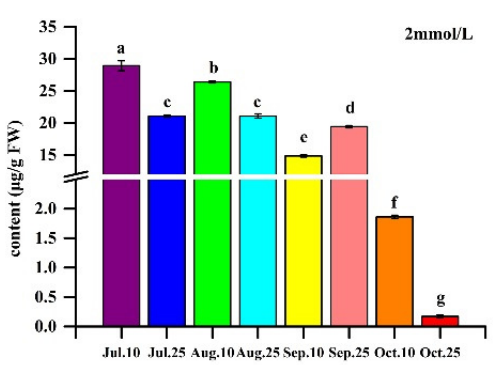

date

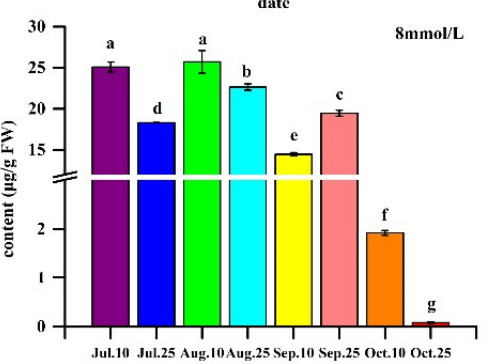

date

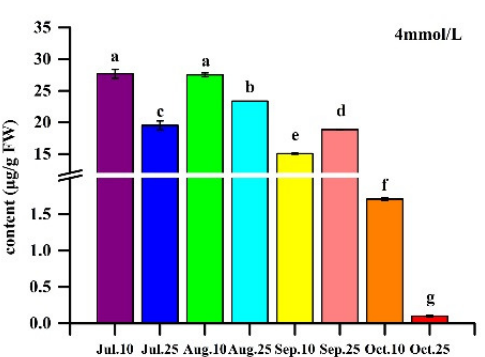

date

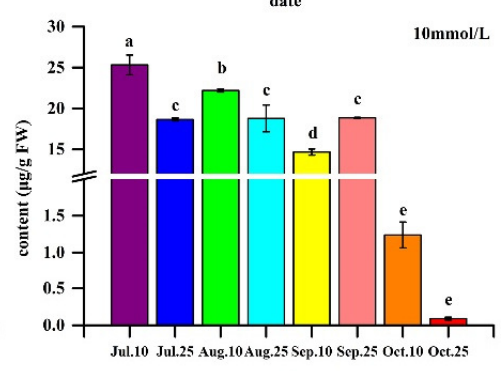

date

Figure 3. Effect of $\mathrm{GA}_{3}$ on the content of endogenous $\mathrm{GA}_{3}$ in ginkgo leaves. Endogenous $\mathrm{GA}_{3}$ content in ginkgo leaves at different peroids $(\mathrm{A})$ and endogenous $\mathrm{GA}_{3}$ content in ginkgo leaves treated with different concentrations of $\mathrm{GA}_{3}(\mathrm{~B})$ 
Effect of $\mathrm{HA}_{3}$ on ginkgolide content in ginkgo leaves

We detected the ginkgolide content in G. biloba leaves treated with different concentrations of $\mathrm{GA}_{3}$ to analyse the effect of $\mathrm{GA}_{3}$ treatment on ginkgolide content. As shown in Figure 4, ginkgolide content under different concentrations of $\mathrm{GA}_{3}$ showed similar trends in different periods. In the whole year of harvesting, the ginkgolide content of the $4 \mathrm{mmol} \mathrm{L}^{-1}$ treatment group was significantly higher than that of the control group, especially when the ginkgolide content reached the peak of the entire harvest season on August 25. At this time, the ginkgolide content in the $4 \mathrm{mmol} \mathrm{L}^{-1}$ treatment group was the highest $\left(4,770 \mu \mathrm{g} \mathrm{g}^{-1} \mathrm{DW}\right)$. Subsequently, the ginkgolide content of the treatment and control groups began to decrease. After reaching the "valley bottom" on September 10, the ginkgolide content of the $4 \mathrm{mmol} \mathrm{L}^{-1}$ treatment group was $4,010 \mu \mathrm{g} \mathrm{g}^{-1} \mathrm{DW}$, which was still higher than that of other treatment groups. By the time of sampling on September 25, the ginkgolide content reached the second highest value of the whole year, and the level of $4 \mathrm{mmol} \mathrm{L}^{-1}\left(4,660 \mu \mathrm{g} \mathrm{g}^{-}\right.$ ${ }^{1} \mathrm{DW}$ ) was significantly higher than that of the other groups. This ginkgolide content was greatly higher than that of the other groups. Subsequently, the ginkgolide content of each treatment group began to decrease until the end of sampling. The ginkgolide content remained at a high level during the entire picking period in August and then began to decline. However, the ginkgolide content rose again in late September, reached the second peak of the whole year, and then began to decline. During the two peak periods on August 25 and September 25 , the total terpene content of the $10 \mathrm{mmol} \mathrm{L}^{-1}$ treatment group was significantly lower than that of the control group. This result indicated that the $10 \mathrm{mmol} \mathrm{L}^{-1}$ treatment level might have exceeded the optimal treatment concentration. Compared with the whole harvest period, the annual average ginkgolide content of the $4 \mathrm{mmol} \mathrm{L}^{-1}$ treatment group was the highest.

\section{Discussion}

\section{Effect of $\mathrm{GA}_{3}$ on endogenous hormones in ginkgo leaves}

In this study, the IAA contents of all experimental groups were significantly higher than that of the control group after exogenous $\mathrm{GA}_{3}$ was sprayed. Giuliano et al. (1993) found that $\mathrm{GA}_{3}$ can promote the synthesis and increase the content of IAA by inhibiting the production of IAA oxidase and preventing the decomposition of IAA. In this study, it was found that the difference of IAA content between the treatment group and the control group increased with the delay of time in the early sampling period. This difference may be due to the accumulation of synthesized IAA content after the inhibition of IAA oxidase activity under the influence of exogenous $\mathrm{GA}_{3}$ at the early stage of treatment (Wu et al., 2001). At the same time, ABA gradually increased and inhibited the outward transport of IAA. Hence, the content of IAA in the treatment group was more different from the control group. However, the influence of exogenous $\mathrm{GA}_{3}$ was gradually weakened, IAA oxidase was increased, and IAA metabolism was strengthened with the continuation of sampling. Therefore, the difference in content gradually decreased in the later sampling period. As shown in Figure 2, the ABA content of each treatment was approximately similar to the change trend in the control group. At the end of sampling, the trend of $\mathrm{ABA}$ content was similar between groups, and no significant difference was observed possibly due to the disappearance of exogenous $\mathrm{GA}_{3}$ and the decrease of ambient temperature in the later stage. The ABA anabolic pathway with GGPP as the synthesis precursor returned to normal; therefore, the difference in $\mathrm{ABA}$ content gradually decreased, and this difference gradually disappeared by the end of sampling. Exogenous GA3 can inhibit the synthesis of GA3-oxidase and 3 $\beta$-hydroxylase via feedback to inhibit the endogenous GA3 anabolic process, resulting in a decrease in its content (Zhu et al., 2007; Yamaguchi, 2008; Gil and García-Martinez, 2010). In our experiment, the endogenous $\mathrm{GA}_{3}$ detected was significantly lower than the $\mathrm{GA}_{3}$ content of the control group, which was consistent with the results of Guo et al. (2000). 
A
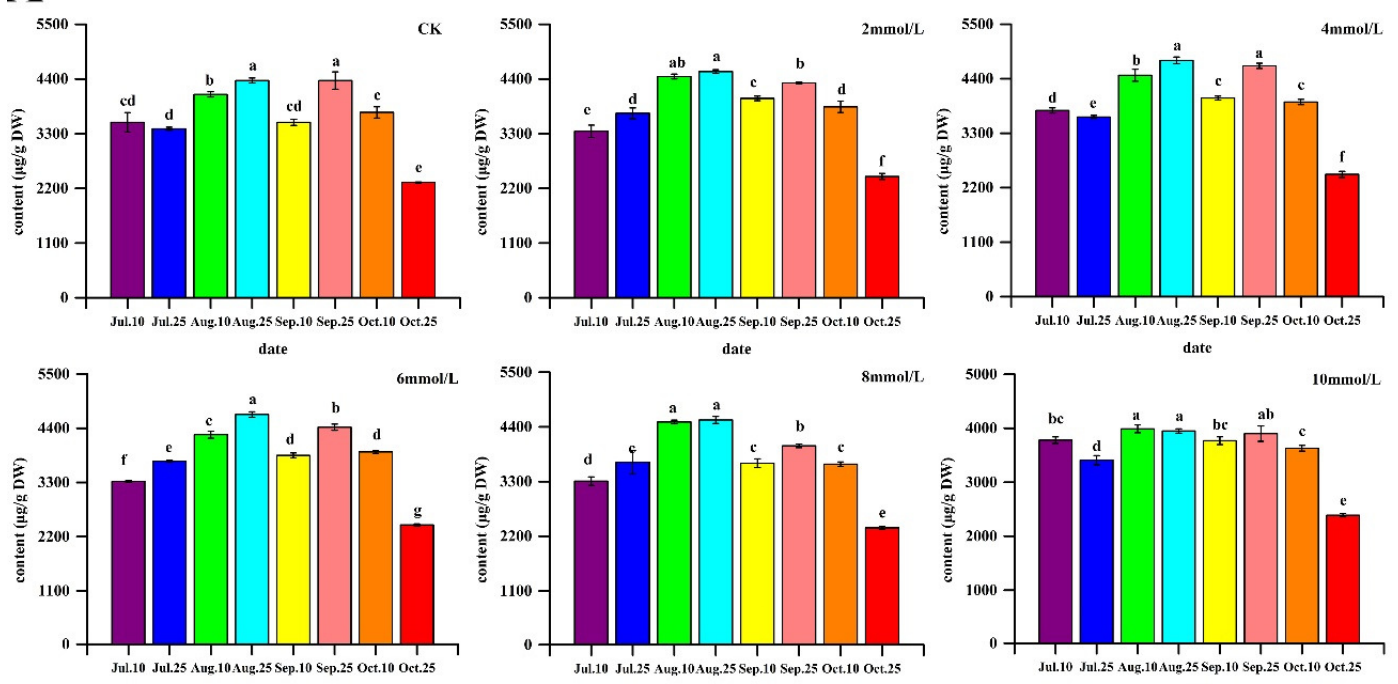

\section{B}

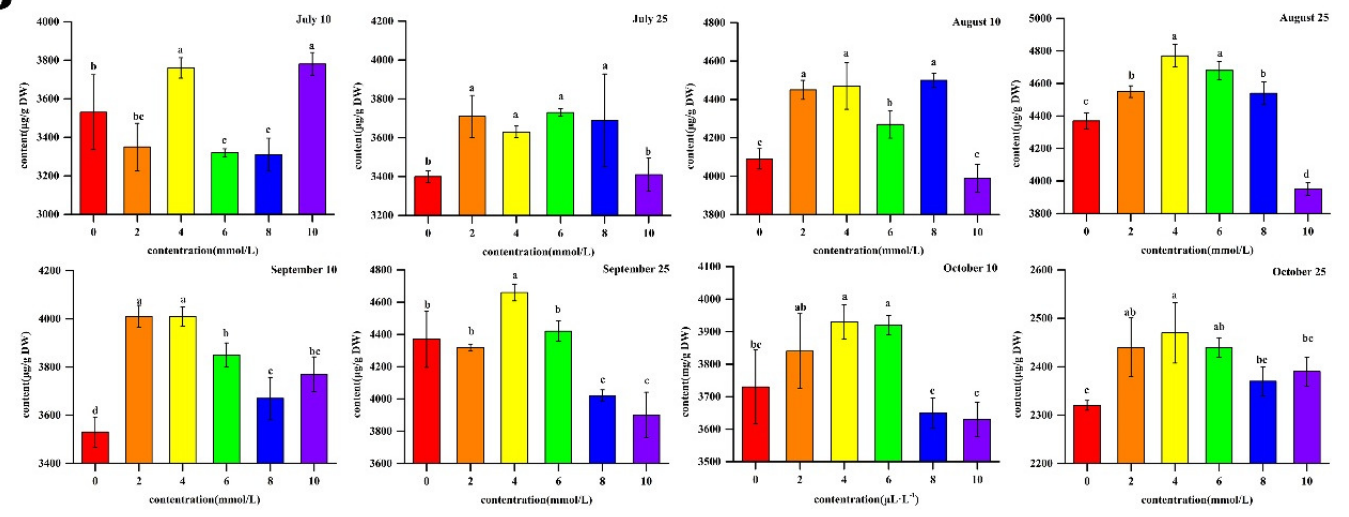

Figure 4. Effect of $\mathrm{GA}_{3}$ on the content of endogenous ginkgolide in ginkgo leaves. Endogenous ginkgolide content in ginkgo leaves at different periods (A) and endogenous ginkgolide content in ginkgo leaves treated with different concentrations of $\mathrm{GA}_{3}(\mathrm{~B})$

\section{Effect of $G A_{3}$ on ginkgolide content in ginkgo leaves}

$\mathrm{GA}_{3}$ is a kind of functional growth-regulating hormone that can significantly promote plant growth, delay plant senescence, and stimulate plant cell division, including cell division and cell enlargement. $\mathrm{GA}_{3}$ can promote DNA synthesis and reduce cell wall stretch ability; hence, current research focuses on the effects of $\mathrm{GA}_{3}$ on watermelon growth cycle and fruit tree bearing (Ju and Wang, 2002). GA 3 can inhibit the accumulation of GA20-oxidase and 3-beta hydroxylase mRNA via feedback. The study of Xu et al. (2011) and Xie et al. (2002) showed that the spray of growth regulator on ginkgo had an effect on the content of ginkgolides.

The effect of exogenous $\mathrm{GA}_{3}$ on ginkgolide content was multifold. First, exogenous $\mathrm{GA}_{3}$ enhanced the photosynthesis of $G$. biloba. The study of $\mathrm{Li}$ et al. (2010) showed that applying exogenous $\mathrm{GA}_{3}$ can improve the net photosynthetic rate and stomatal conductance of sugarcane. Therefore, exogenous $\mathrm{GA}_{3}$ can affect the content of primary products and secondary metabolites of $G$. biloba and increase the carbon source of the plant. $\mathrm{GA}_{3}$ provides more precursors for the synthesis of ginkgolides and finally improves the content of ginkgolides. Second, exogenous $\mathrm{GA}_{3}$ can cause the feedback inhibition of the synthesis of GA3-oxidase and $3 \beta$-hydroxylase 
to inhibit the anabolic processes of endogenous $\mathrm{GA}_{3}$. In this experiment, endogenous $\mathrm{GA}_{3}$ detected in treatment groups were significantly lower than the $\mathrm{GA}_{3}$ content of the control group probably because the exogenous $\mathrm{GA}_{3}$ feedback inhibited the synthesis of endogenous $\mathrm{GA}_{3}$ and thus decreased its content. The inhibition of endogenous $\mathrm{GA}_{3}$ synthesis increased GGPP, a substrate for the synthesis of ginkgolides. Therefore, ginkgolide content was increased. Third, IAA regulates the synthesis of GGPP in the DXP pathway, and although the concentration of precursors for $\mathrm{GA}_{3}$ and ginkgolides was increased, the ginkgolide content synthesized from precursors was increased due to the inhibition of endogenous hormone synthesis.

From the analysis of each treatment concentration, ginkgolide content in the $10 \mathrm{mmol} \mathrm{L}^{-1}$ treatment group was remarkably lower than the control group during the two peak periods, August 25 and September 25. Therefore, this concentration may be higher than the optimal treatment concentration. The $4 \mathrm{mmol} \mathrm{L}^{-1}$ treatment group had substantially higher ginkgolide content than the other treatment groups at the two peak periods. The three concentrations $\left(2,6\right.$, and $\left.8 \mathrm{mmol} \mathrm{L}^{-1}\right)$ had a lesser tendency to influence the level of ginkgolide content than the $4 \mathrm{mmol} \mathrm{L}^{-1}$ treatment, especially in the peak period of September 25 . These three treatment groups $\left(2,6\right.$, and $\left.8 \mathrm{mmol} \mathrm{L}^{-1}\right)$ were not significantly different from that of the control group or lower than that of the control group Only the $4 \mathrm{mmol} \mathrm{L}^{-1}$ treatment group had significantly higher ginkgolide than the control and other treatment groups. Therefore, the $4 \mathrm{mmol} \mathrm{L}^{-1}$ treatment level may be the optimal treatment concentration.

In addition, exogenous $\mathrm{GA}_{3}$ also has a certain impact on the optimal harvesting period of ginkgo leaves. Exogenous $\mathrm{GA}_{3}$ had no obvious effect on the peak time of ginkgolides but remarkably increased the ginkgolide content, extended the harvest time of ginkgo leaves, and the ginkgolide content of more than $0.4 \%$ was changed from 40 days in the control group to 60 days in treatment groups, greatly increasing the harvesting time.

\section{Conclusions}

Although the effects of different concentrations of $\mathrm{GA}_{3}$ on the ginkgolide content are different, it can be effectively used to extend the harvest time of ginkgo leaves. Further research is needed on the possible mechanisms of $\mathrm{GA}_{3}$ regulation.

\section{Acknowledgements}

This study was supported by the National Natural Science Foundation of China (No. 31971693) and Yangtze University Outstanding Doctoral and Master's Degree Thesis Cultivation Program.

\section{Conflict of Interests}

The authors declare that there are no conflicts of interest related to this article.

\section{References}

Gil J, García-Martinez JL (2000). Light regulation of gibberellin A1 content and expression of genes coding for GA 20-oxidase and GA 3ß-hydroxylase in etiolated pea seedlings. Physiologia Plantarum 108:223-229.

Giuliano G, Bartley GE, Scolnik PA (1993). Regulation of carotenoid biosynthesis during tomato development. The Plant Cell 5:379-387. 
Guo Z, Feng Y, Liu R (2000). Control of taxol and taxanes biosynthesis by growth regulators. Natural Product Research and Development 12:22-26.

Hu W, Sun T, Tian Y, Wang K (2017). Ginkgolide B modulates BDNF expression in acute ischemic stroke. Journal of Korean Neurosurgical Society 60:391-396.

Ju XR, Wang HF (2002). Influence of microwave desiccation on effective components of ginkgo biloba leaves. Food Science 23:56-58.

Ke L, Li XJ, Du G, Xu L (2016). Characterizations of the hydrolyzed products of ginkgolide A and ginkgolide B by liquid chromatography coupled with mass spectrometry. Journal of Pharmaceutical and Biomedical Analysis 118:113-122.

Li PC, Yu SL, Fu XF, Zheng QQ (2010). Effects of GA_3 on the characteristics of photosynthesis and chlorophyll fluorescence of grape leaves during the maturation stage. Acta Agriculturae Boreali-Occidentalis Sinica 19:144-149.

Liao YL, Xu F, Cheng SY (2006). Research progress in the ginkgolides of ginkgo leaf. Journal of Anhui Agricultural Sciences 34:4956-4958.

Liao YL, Xu F, Zhu J, Wang Y, Cheng SY (2008). Separation and determination of terpene trilactiones by gas chromatography with wide bore capillary column. Acta Agriculturae Boreali-Occidentalis Sinica 17:146-149.

Niu YL, Zhao Q, Zhang XH, Ai QS, Song SS (2015). Research progress on the role and regulation mechanism of gibberellin signal in response to abiotic stress. Biotechnology Bulletin 31:31-37.

Tian JF, Liu Y, Chen KJ (2017). Ginkgo biloba extract in vascular protection: molecular mechanisms and clinical applications. Current Vascular Pharmacology 15:532-548.

Ülger S, Atmaca S, Demiral S (2018). The effects of GA3 treatment on yield, carbohydrate, and endogenous hormone changes in Memecik olive cultivar. Turkish Journal of Agriculture and Forestry 42:75-81.

Vera-Sirera F, Gomez MD, Perez-Amador MA (2016). Chapter 20-della proteins, a group of gras transcription regulators that mediate gibberellin signaling. Plant Transcription Factors 313-328.

Wu J, Zhong JH, Xu K, Wei QP, Wei ZL (2001). Effects of exogenous GA_3 on fruit development and endogenous hormones in fujiminori grape. Journal of Fruit Science 18:209-212.

Xie BD, Wang HT, Wu GY, Song KH (2002). The influence of ethrel on contents of flavone-lactone in gingko leaves. Journal of Shandong Forestry Science and Technology 3:1-3.

Xu F, Zhang W, Sun N, Li L, Cheng S, Wang Y (2011). Effects of chlorocholine chloride on photosynthesis metabolism and terpene trilactones biosynthesis in the leaf of Ginkgo biloba. Acta Horticulturae Sinica 38:2253-2260.

Yamaguchi S (2008). Gibberellin metabolism and its regulation. Annual Review of Plant Biology 59:225-251.

Ye J, Cheng S, Zhou X, Chen Z, Kim S, Tan J, ... Zhu Y (2019). A global survey of full-length transcriptome of Ginkgo biloba reveals transcript variants involved in flavonoid biosynthesis. Industrial Crops and Products 139:111547.

Ye J, Zhang X, Tan J, Xu F, Cheng S, Chen Z, Zhang W, Liao Y (2020). Global identification of Ginkgo biloba microRNAs and insight into their role in metabolism regulatory network of terpene trilactones by high-throughput sequencing and degradome analysis. Industrial Crops and Products 148:112289.

Zhang C, Zhou T, Zheng W, Li J, Xiao C, Gong A, Jiang W (2018). Effects of exogenous gibberellin on cytokinin content variation in Pseudostellaria heterophylla root and metabolism key enzyme gene expression. Journal of Southern Agriculture 49:2141-2147.

Zhu J, Xu F, Cheng SY (2010). A study on the correlation of terpene lactone and endogenous hormones in Ginkgo biloba leaves. Hubei Agricultural Sciences 49:2807-2801.

Zhu J, Xu F, Liao YL, Wang Y, Chen SY (2007). Progress in studies of ginkgolides contents regulating. Chinese Agricultural Science Bulletin 23:301-305.
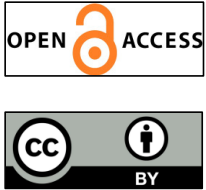

The journal offers free, immediate, and unrestricted access to peer-reviewed research and scholarly work. Users are allowed to read, download, copy, distribute, print, search, or link to the full texts of the articles, or use them for any other lawful purpose, without asking prior permission from the publisher or the author.

License - Papers published in Notulae Botanicae Horti Agrobotanici Cluj-Napoca are Open-Access, distributed under the terms and conditions of the Creative Commons Attribution (CC BY) License. (C) Articles by the authors; UASVM, Cluj-Napoca, Romania. The journal allows the author(s) to hold the copyright/to retain publishing rights without restriction. 